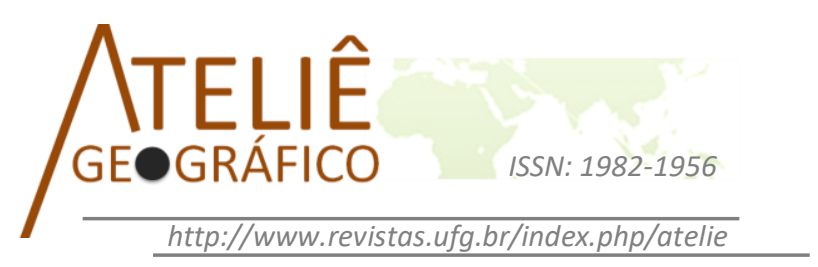

\title{
La influencia de la edad en la inserción de trabajo como dependiente o independiente y su comportamiento a nivel espacial. Argentina (2001 y 2010)
}

\author{
A influência da idade na inserção do trabalho como independentes \\ ou dependentes e seu comportamento a nível de espaço. Argentina \\ (2001 e 2010)
}
The influence of age on the insertion of work as independent or dependent and their behavior at the level of space. Argentina (2001 and 2010)

Fernando Ariel Manzano

Universidad Nacional del Centro de la Provincia de Buenos Aires

fernando14979@hotmail.com

\begin{abstract}
Resumen
La Argentina tuvo un crecimiento positivo de su economía en los últimos dos periodos intercensales. Entre 1991-2001 se produjo un creciente aumento en el nivel del desempleo, alcanzando valores máximos históricos al final de este periodo, en contraposición durante el último periodo intercensal se produjo un crecimiento record del total de ocupados. En el marco de las notables diferencias en el tamaño del mercado de trabajo en los años censales 2001 y 2010, la problemática investigada consiste en el análisis de las distintas participaciones relativas de las categorías ocupacionales de los trabajadores y trabajadoras según la edad de los mismos. Los ocupados más jóvenes presentan el mayor porcentaje de asalariados en el sector privado (en mayor medida en el caso de las mujeres) y la menor participación de trabajadores independientes. Conforme se incrementa la edad, esta situación se invierte, disminuyendo las posibilidades de ser un trabajador dependiente en ambos años censales. El objetivo consiste en verificar si estos patrones a nivel total país, se corroboran a una escala espacial inferior.
\end{abstract}

Palabras Claves: Edad; Trabajado dependiente; Trabajador cuenta propia; Jerarquías urbanas.

\section{Resumo}

A Argentina teve um crescimento positivo da sua economia nos últimos dois períodos entre censos. Entre 1991-2001 houve um crescente aumento do nível de desemprego, atingindo 
valores máximos históricos no final deste período, em contraste durante o último período intercensitárias viu um crescimento recorde do número total de trabalhadores por conta de outrem. No quadro das notáveis diferenças no tamanho do mercado de trabalho nos anos censitários de 2001 e 2010, problema investigado consiste na análise das diferentes partes relativas de as categorias ocupacionais de trabalhadores e trabalhadoras de acordo com a idade dos mesmos. Os territórios mais jovens têm a maior percentagem de assalariados do sector privado (em maior medida no caso de mulheres) e a menor participação dos trabalhadores independentes. À medida que a idade aumenta, essa situação é revertida, diminuindo a capacidade de ser um empregado em ambos os anos censitários. O objetivo é verificar se esses padrões ao nível total país, corroboram a uma menor escala espacial.

Palavras-chave: Idade; Trabalhou dependentes; Trabalhador por conta própria; Hierarquias urbanas.

\begin{abstract}
:
Argentina had a positive growth of its economy in the last two periods between censuses. Between 1991-2001 there wasa growing increase in the level of unemployment, reaching historical maximum values at the end of this period, in contrast during the last intercensal period saw a growth record of the total number of employed persons. In the framework of the notable differences in the size of the labor market in the census years 2001 and 2010, the problem investigated consists in the analysis of the different relative shares of the occupational categories of workers and women workers according to the age of the same. The territories more young people have the highest percentage of wage earners in the private sector (to a greater extent in the case of women) and the smaller share of independent workers. As age increases, this situation is reversed, decreasing the ability to be a dependent employee in both census years. The objective is to check if these patterns to total level country, corroborate to a lower spatial scale.
\end{abstract}

Keywords: Age; worked dependent; self-employed person; urban hierarchies.

\title{
Introducción
}

La Argentina durante los dos últimos periodos intercensales -1991-2001 y 2001-2010-, presentó un crecimiento positivo en su economía, sin embargo resultan notables los contrastes respecto a lo acontecido en el mercado laboral entre ambos periodos (MANZANO y VELÁZQUEZ, 2016).

Desde el año 1994 hasta el 2001, se destacó un creciente aumento en el nivel del desempleo hasta alcanzar valores máximos en términos históricos, coincidente con el nivel más bajo de empleo público desde los años setenta (ZELLER y RIVKIN, 2003), en el contexto de la peor crisis de la económica argentina producida en el año $2001^{1}$. En cambio durante el último periodo intercensal, el mercado laboral transitó un camino opuesto, se produjo un fuerte descenso de la tasa de desocupación, y en particular a partir del año 2005, también se evidenció un incremento de la demanda de empleo en el sector público (GHERARDI y ZIBECCHI, 2010).

\footnotetext{
${ }^{1}$ La crisis de 2001 representó un desastre social de magnitudes inigualables para los argentinos. Luego de la destrucción del régimen monetario de la convertibilidad, se produjo una mega-devaluación, seguido de un abrupta caída de la producción, y enfrentando el default más importante de la historia económica internacional (NOVICK, 2006).
} 
El comportamiento de los mercados de trabajo en general, se encuentra lejos de poder considerarse como homogéneo ${ }^{2}$. Respecto a la dinámica del mercado laboral argentino en el último periodo intercensal, además del inusitado incremento del nivel de empleo (que generó un descenso de la tasa de desocupación de $22 \%$ a $6 \%$ entre 2001 y 2010, respectivamente), se destacó una gran heterogeneidad en las condiciones de los empleos (PÉREZ, DELEO Y FERNÁNDEZ MASSI, 2013).

En el marco del análisis de la segmentación del empleo argentino en los años 2001 y 2010, buscamos indagar respecto a los comportamientos de las categorías ocupacionales según la edad de los trabajadores y trabajadoras, comparando la situación a nivel más agregado (los resultados para el total país), y a una escala inferior determinada por áreas geográficas urbanas, generadas en base a la categorización de las jerarquías de los aglomerados urbanos y las regiones del país, de manera de corroborar si los patrones existentes para el total país, también se encuentran en áreas espaciales menores.

\section{Consideraciones teóricas y estrategia metodológica}

Bertranou y Saravía (2009), establecen una relación positiva entre la edad y la probabilidad de estar autoempleado -ya sea como patrón o trabajador cuenta propia-. Dada por válida la afirmación anterior, se deduce de la misma la existencia de una relación inversa entre la edad y la posibilidad de tener un empleo dependiente -la categoría ocupacional mayoritaria corresponde a los asalariados, mientras que los trabajadores familiares en términos de escasa cantidad de puestos de trabajo que aporta, resulta una categoría ocupacional marginal-. Cabe destacar que los datos que muestra la Organización Internacional del Trabajo [en adelante OIT (2006)] para los países de América Latina durante el periodo 1995-2005, reflejan una correlación negativa entre la edad de las personas y la participación en el empleo asalariado. Así como también los resultados sobre Estados Unidos de Rissman (2006), que expresan el aumento del porcentaje de trabajadores independientes ${ }^{3}$ con la edad.

Para muchos jóvenes el trabajo dependiente, mayoritariamente como asalariados informales, representa la posibilidad de ingreso a su primer empleo, y a comenzar a acumular habilidades y experiencias (TORNAROLLI y CONCONI, 2007). Mientras que en el otro extremo de la estructura etaria, se destaca el alto porcentaje del empleo independiente, relacionado con la exclusión del mercado laboral asalariado de

\footnotetext{
${ }^{2}$ El aparato productivo de la región se caracteriza por una alta heterogeneidad estructural, su origen en parte se debe a la segmentación de los mercados de capital humano (PINTO, 1998; RAMOS, 1993). Debido a las características del mercado de trabajo, la heterogeneidad de la estructura productiva retroalimenta la segmentación laboral, y si bien existe cierta movilidad de la mano de obra entre los segmentos, hay trabajadores con el mismo grado de capacitaci6n que perciben remuneraciones diferentes (MÁRQUEZ y MEZZERA, 1988 apud WELLER, 1998).

${ }^{3}$ El trabajador independiente se diferencia de aquel vinculado por contrato de trabajo en que éste presta sus servicios personales con plena autonomía, sin observación a órdenes impartidas por el contratante, salvo las necesarias para la buena ejecución de la labor contratada (ROJAS CHÁVEZ, 2005).
} 
los trabajadores en edades adultas, asimismo, sobre todo el cuentapropismo se adapta a condiciones laborales más flexibles (BERTRANOU, 2007), permitiendo mantenerse en el mercado de trabajo en edades avanzadas. También, considerando el grado de control sobre los medios de trabajo a lo largo de la vida activa, en el caso de los patrones existen más chances de permanecer ocupados a mayor edad (SALA, 2011).

Bertranou (2007) en un estudio comparativo realizado sobre los trabajadores independientes y la cobertura de la seguridad social en Argentina, Chile y Uruguay, encuentra que la edad promedio de los trabajadores independientes es mayor que la de los trabajadores asalariados, como consecuencia de la mayor incidencia del autoempleo entre los adultos mayores (BERTRANOU y MAURIZIO, 2011).

Entre las diferentes condiciones laborales existentes en cada una de las modalidades identificadas de trabajo por cuenta propia, respecto a la comparación de los ingresos, los trabajadores cuenta propia profesionales obtienen ingresos similares a los de los asalariados registrados en las mismas ocupaciones, y que a su vez son mayores a los obtenidos por sus pares insertos en empleos no registrados en las mismas ocupaciones (LEPORE y SCHLESER, 2006).

El marco teórico de referencia desde el cual analizaremos el mercado laboral, son las teorías de la segmentación ${ }^{4}$. Estas sostienen que no existe un sólo mercado de trabajo (KERR, 1954; PIORE y DOERINGER, 1971), sino un conjunto de segmentos en los cuales coexisten distintos sectores con características y condiciones de trabajo diferentes y escasa movilidad de trabajadores entre los sectores (JIMÉNEZ, 2011). Bajo esta concepción se admite la presencia de fuerzas ajenas al mercado, en oposición a la teoría neoclásica (KERR, 1988). Economistas partidarios de este enfoque, analizando las operaciones reales en los mismos, advierten que la movilidad laboral tiene una influencia mucho más baja sobre las remuneraciones que en relación a la prevista por el modelo competitivo de la teoría neoclásica ${ }^{5}$, destacando dos motivos, por un lado la incompleta o errónea información de los trabajadores, por otro, que el proceso de búsqueda de empleo no está guiado por una persecución incansable de la maximización de la utilidad, sino por la búsqueda de un empleo suficientemente satisfactorio (FERNÁNDEZ-HUERGA, 2010).

La información utilizada en este trabajo corresponde a los microdatos de los dos últimos censos poblacionales de Argentina $^{6}$ (2001 y 2010), estos nos permiten realizar diferentes procesamientos para analizar esta problemática en mayor profundidad.

\footnotetext{
${ }^{4}$ Los antecedentes de la teoría de segmentación suelen situarse en unos grupos economistas dedicados a los temas laborales durante los años cuarenta y cincuenta, como R. Lester, J. Dunlop, C. Kerr, L. Reynolds, C. Myers, L. Fisher, A. Ross o R. Livernash.

${ }^{5}$ La teoría neoclásica, supone un mercado laboral homogéneo, además considera que el desempleo es voluntario y la productividad marginal del trabajador está determinada positivamente por el nivel de capital humano del trabajador (NEFFA, 2001).

${ }^{6}$ Utilización del programa Redatam+SP (CEPAL/ Centro Latinoamericano y Caribeño de Demografía [CELADE]).
} 
Respecto de la dimensión espacial, proponemos una delimitación de 22 áreas geográficas urbanas, que surgen de la combinación de las 5 jerarquías urbanas tomadas del clásico trabajo de Vapñarsky y Gorojovsky ${ }^{7}$ (1990)-, y las seis regiones estadísticas $^{8}$ del territorio nacional. Es decir, cada una de ellas está conformada por aglomeraciones pertenecientes a una misma región y comparten el mismo nivel de jerarquía urbana.

\section{Efectos de las variables demográficas básicas en la inserción de los ocupados en el mercado de trabajo a nivel total país.}

Suele denominarse como población en edad de trabajar -en adelante PET-, al grupo de las personas de 14 años y más, el cual tuvo un incremento de algo más del $13 \%$ entre los años 2001 y 2010. Al interior de la PET, considerando la división según grupos de edad, se destacan las variaciones diferenciales entre los mismos, debido a los cambios que se producen en la fecundidad, mortalidad y las migraciones.

En la Figura 1 se presenta la PET dividida en cinco intervalos de edad, en los años 2001 y 2010. Los grupos de edad de mayor aumento relativo en ambos sexos, fueron los de 26 a 40 años y 56 a 65 años -los restantes grupos crecieron por debajo del promedio-

Comparando las estructuras de las PET de los dos últimos censos, resulta que el grupo poblacional más cuantioso en el año 2001 fue el de 14 a 25 años, mientras que en el año 2010 correspondió al de 26 a 40 años, en cada uno de los sexos. Además en el caso de los varones, el grupo de 56 a 65 años se encontraba en la última posición en el año 2001, y ascendió un puesto en el año 2010.

Se define como población económicamente activa - en adelante $\mathrm{PEA}^{9}-$, al conjunto de personas que se encuentran activamente en el mercado de trabajo, tanto ocupados como desocupados.

La estructura de la PEA o de la oferta de empleo presentó una concentración del 64\% de la misma entre los 26 y 55 años en los años 2001 y 2010 . Esta franja etaria representó el 48,7\% de la PET en 2001 y 49,8\% en el año 2010. En el último periodo

\footnotetext{
${ }^{7}$ Las cinco categorías urbanas consideradas serán: metrópolis y ciudades grandes (más de 1.000 .000 de habitantes); aglomeraciones de tamaño intermedios (en adelante ATIs), grandes (400.000-999.999 habitantes); ATIs medias (50.000-399.999 habitantes); ATIs pequeñas (20.000-49.999 habitantes); y pueblos grandes (2.000-19.999 habitantes (VAPÑARSKY y GOROJOVSKY, 1990). Quedan excluidas las aglomeraciones de menos de 2 mil habitantes, correspondientes a la población rural agrupada y rural dispersa.

${ }^{8}$ Propuesta por el Instituto Nacional de Estadística y Censos -basada en límites políticos provinciales, salvo para el caso de la región Metropolitana- (VELÁZQUEZ, 2008). La división regional definida será la siguiente: Noroeste (NOA), Noreste (NEA), Cuyo, Pampeana, Metropolitana y Patagónica.

${ }^{9}$ La PEA se considera, generalmente, como un indicador de la oferta de trabajo o de la disponibilidad del factor trabajo en la economía en un momento determinado. Resulta fundamental su papel en el funcionamiento del mercado de trabajo, de hecho se puede afirmar que se constituye en uno de los criterios para determinar el grado de desarrollo socioeconómico de un país (ABELLÁN, 1998 apud. GOYES, 2009).
} 
intercensal el aumento fue del $22,0 \%$ en los varones, y en las mujeres de $32,2 \%$, una diferencia significativa en comparación con las variaciones en la PET (en que sólo influyen las modificaciones de las variables de carácter netamente demográfico). De esta comparación surge que las mujeres presentan un mayor incremento en la participación en el mercado de trabajo que los varones entre los años 2001 y 2010.

Entre los grupos de edad determinados, los grupos de 26 a 40 años, de 56 a 65 años, y más de 65 años tuvieron un aumento relativo intercensal mayor al promedio de la PEA, siendo marcadamente superior el aumento de las mujeres en relación a los varones.



Figura 1. Estructura de la población potencialmente activa por sexo y grupos de edad, según condición de actividad Argentina. Años 2001 y 2010

Fuente: Elaboración personal en base a datos de los Censos Nacionales de Población de 2001 y 2010 , procesado con Redatam $+\mathrm{Sp}$.

Respecto a la demanda de empleo, entre los años 2001 y 2010, se produjo un incremento del nivel de empleo de $54,4 \%$ para los varones y de $84,3 \%$ para las mujeres, siendo mucho más elevado respecto al crecimiento de la PEA. 
La estructura de los ocupados concentró el 69,6\% y 64,3\% de su totalidad, en 2001 y 2010, respectivamente, entre los 26 y 55 años, una situación más elevada que la descripta en la PEA.

A continuación analizaremos la inserción de los ocupados según la categoría ocupacional ${ }^{10}$. En año 2001 y en el año 2010, alrededor del 50\% del total de los ocupados y ocupadas - siendo el crecimiento intercensal del total de ocupados entre ambos años de un nivel record del 65,6\%-, se insertó como asalariado en el sector privado.

Los asalariados del sector público en los dos últimos censos representaron el $17 \%$ aproximadamente del total de los ocupados, y alrededor del $25 \%$ de las asalariadas. La categoría de trabajadores por cuenta propia, en los varones significó el $23 \%$ del total de los ocupados en el 2001 y el $20 \%$ en el año 2010 , y en las mujeres representó el 14\% de todas las ocupadas en 2001 y el $18 \%$ en el año 2010. Vemos que la diferencia en la participación relativa de los cuenta propia en cada sexo se redujo entre ambos años. Ver Figura 2.

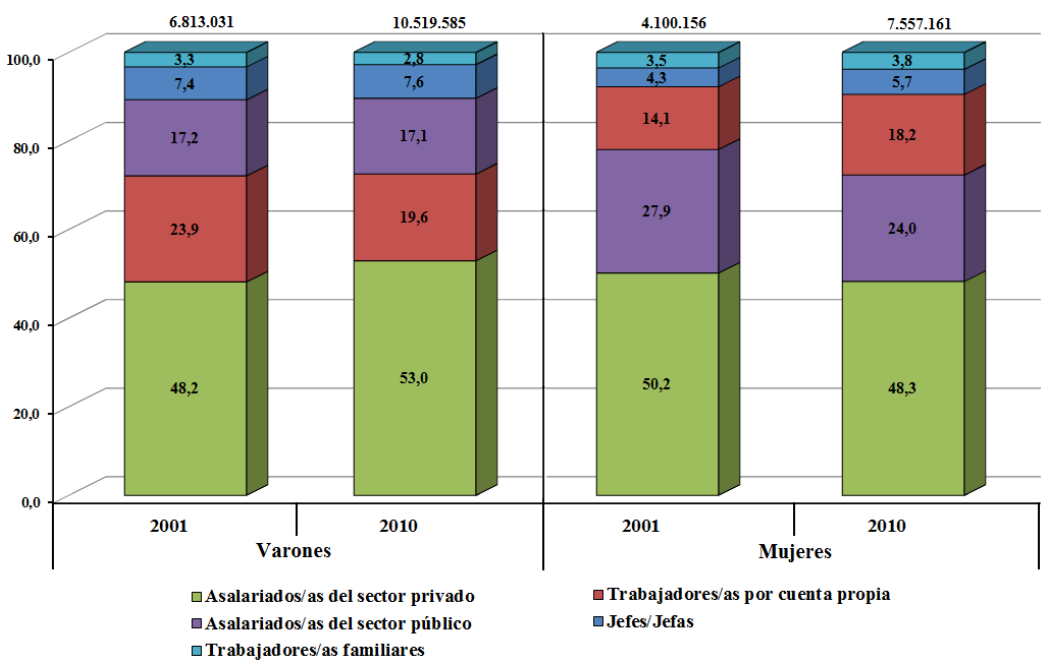

Figura 2. Distribución de los trabajadores/as según categoría ocupacional (en \%). Argentina. Años 2001 y 2010

Fuente: Elaboración personal en base a datos de los Censos Nacionales de Población de 2001 y 2010 , procesado con Redatam+Sp.

\footnotetext{
${ }^{10}$ En el censo del año 2001 pregunta 31 , en el trabajo principal es obrero o empleado, patrón, trabajador por cuenta propia, o trabajador familiar, y la pregunta 32, trabaja en un empleo estatal (nacional, provincial o municipal) o un empleo del sector privado. En el año 2010 la pregunta 32, En ese trabajo es obrero(a) o empleado(a), patrón(a), trabajador(a) por cuenta propia, trabajador(a) familiar. Y la pregunta 32, que responden solos obrero(a) o empleado(a), Trabaja en el sector público nacional, público provincial, público municipal o privado. De ambas preguntas en cada sexo, definimos 5 categorías ocupacionales que son las siguientes: asalariado(a) del sector privado, asalariado (a) del sector público, jefe (a), trabajador(a) cuenta propias, y trabajador(a) familiar.
} 
Los jefes representaron cerca del 7,5\% del total de los ocupados en los dos últimos censos, y las jefas pasaron de ser algo más del $4 \%$ de todas las ocupadas en 2001 a cerca del 6\% en el 2010, por tanto, también se produjo una disminución de la brecha de género en esta categoría ocupacional. La categoría de menor peso relativo correspondió a los trabajadores familiares, alrededor del $3 \%$ en los varones y algo menos del 4\% en las mujeres en los años 2001 y 2010.

En síntesis, se destacan rigideces en la distribución relativa de los ocupados entre las categorías ocupacionales en ambos sexos. Ante un crecimiento de 65,6\% de los puestos de trabajo en el último periodo intercensal, las participaciones relativas de las categorías ocupacionales tuvieron una variación máxima de 4,8 puntos porcentuales (en adelante p.p.) en la categoría de los trabajadores asalariados del sector privado y de $-4,3$ p.p. en los cuenta propia.

A continuación indagaremos si este comportamiento se mantuvo también entre los distintos grupos de edad.

Del total de ocupados de 14 a 25 años, alrededor del $65 \%$ se insertó como asalariados en el sector privado en los dos últimos años censales, y en el caso de las mujeres el $71,9 \%$ en 2001 y el $64,2 \%$ en 2010 . Conforme nos desplazamos hacia grupos de edades superiores, el peso relativo de esta categoría ocupacional descendió de manera continua en cada uno de los sexos, para los dos últimos años censales.

Los trabajadores cuenta propia constituían alrededor del 15\% de los ocupados de entre 14 a 25 años en los censos de los años 2001 y 2010, y en las trabajadoras más jóvenes, el 8,7\% en 2001 y el 15,5\% en 2010. Transitando por los grupos de edades siguientes, el cuentapropismo presentó un aumento de su participación relativa en cada uno de los sexos, en los años 2001 y 2010. La categoría ocupacional de jefes y jefas presentó en el grupo de edad de 14 a 25 años la menor participación relativa en el total de ocupados y ocupadas, respectivamente. El porcentaje de participación se incrementa a medida que se eleva la edad de los trabajadores.

Es decir, cuanto más jóvenes los trabajadores, también menores son las posibilidades de un empleo independiente, y por tanto, mayor la dependencia del trabajo asalariado. Mientras que conforme aumenta la edad, se incrementan las posibilidades de insertarse de manera independiente en el mercado de trabajo.

Respecto a las entradas en el autoempleo, Mandelman y Montes Rojas (2007) sugieren para el caso de Argentina la existencia de mayores probabilidades de convertirse en trabajadores independientes, se produce en los jóvenes con bajo nivel educativo, como en los trabajadores en edades medias (entre 40 y 55 años) con educación universitaria. En contraposición a esta afirmación, a nivel total país los datos utilizados muestran que la participación del trabajo independiente (tanto para los cuenta propia, como para los jefes), se incrementa conforme aumenta la edad de los trabajadores, hallándose el mayor peso relativo en el grupo de más de 65 años, en los dos sexos, para los años 2001 y 2010. 


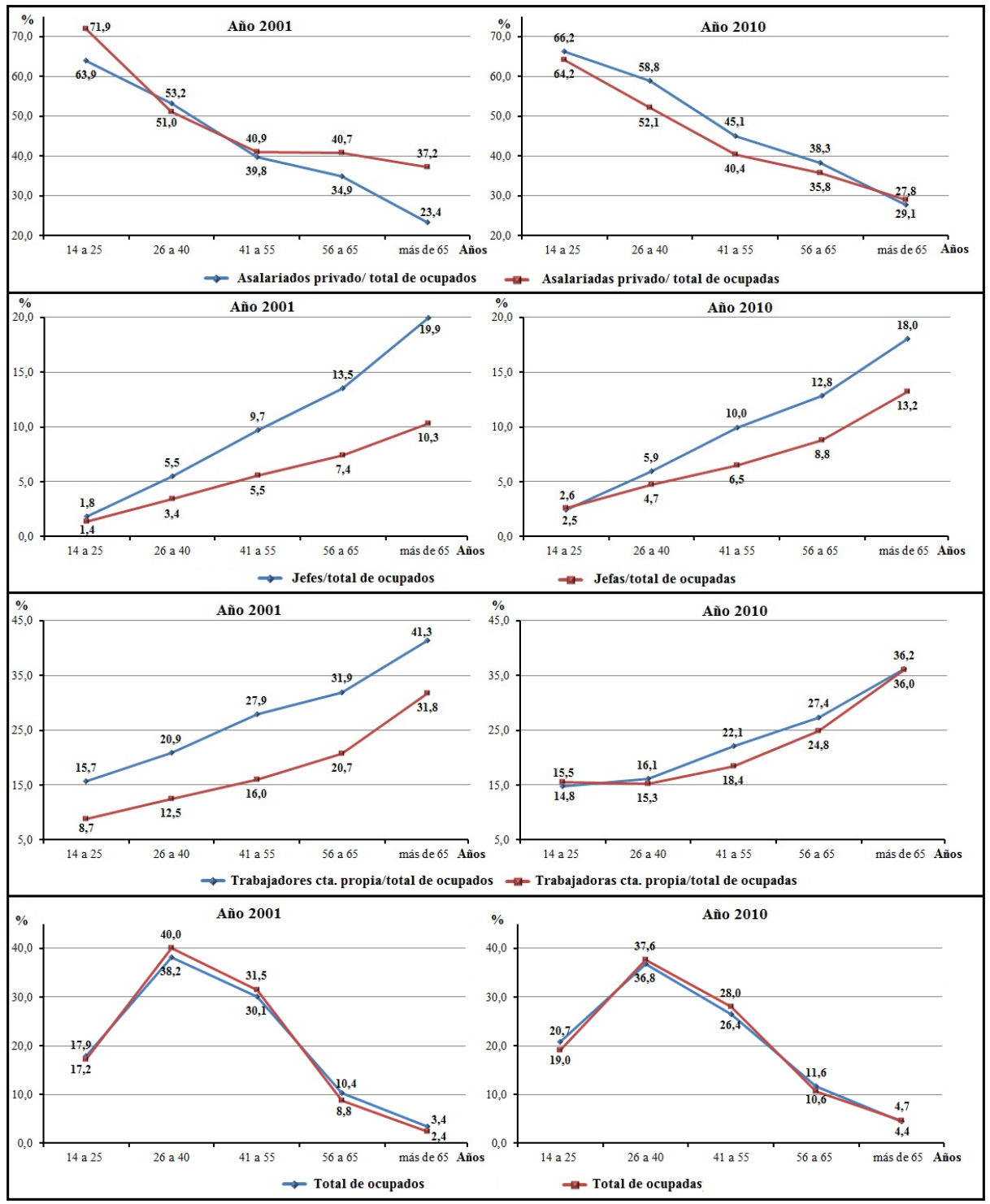

Figura 3. Participaciones relativas de los ocupados en las categorías ocupacionales seleccionadas, según grupos de edad y sexo. Argentina. Años 2001 y 2010.

Fuente: Elaboración personal en base a datos de los Censos Nacionales de Población de 2001 y 2010 , procesado con Redatam $+\mathrm{Sp}$.

Lejos de reflejar una estructura estable, tal como ocurre a nivel agregado en la participación relativa de cada categoría ocupacional en el total de los ocupados y ocupadas. Se destaca el vínculo estrecho de la variable edad de los trabajadores en la 
inserción según categorías ocupacionales. Vemos que a nivel total país la categoría de los asalariados en el sector privado presentó un decrecimiento y las categorías cuenta propia y jefe un incremento relativo en el total de los ocupados a medida que pasamos a grupos de edades superiores, tanto en mujeres como en varones, en los años 2001 y 2010 .

En el apartado siguiente el objetivo es comprobar si la relación mencionada se cumple entre las 22 áreas geográficas generadas de manera de poder validar o no la hipótesis en cuestión.

\section{Los cambios de los ocupados según categoría ocupacional a nivel espacial.}

Como hemos visto, a nivel total país la cantidad de empleo independiente (conformado por las categorías ocupacionales de cuenta propia y jefes), en términos absolutos y relativos en los varones fue superior a las mujeres.

Hemos visto a escala nacional la relación existente entre ciertas categorías ocupacionales y edad de los ocupados y ocupadas, para los dos últimos censos.

A nivel total país, el grupo de edad con mayor cantidad de trabajadores cuenta propia en cada uno de los sexos, fue el de 41 a 55 años en el año 2001. Considerando las 22 aéreas geográficas, en los varones esto no se cumplió en 10 áreas -en las ATIs grandes de la región Pampeana; en las ATIs pequeñas de la Patagonia, y en todas las categorías urbanas de las regiones del Noreste y Noroeste-, y en las mujeres no se cumplió en 14 de las 22 áreas geografías consideradas -en las metrópolis y ATIs medias de la región Pampeana, en las ATIs grandes de Cuyo; en las ATIs medias, pequeñas y pueblos grandes de la región Patagónica; y en todas las categorías urbanas de las regiones del Noreste y Noroeste-, en todas estas áreas el grupo de 26 a 40 años fue el que presentó la mayor cantidad de cuentapropistas . En el año 2010 el grupo de edad con mayor cantidad de trabajadores cuenta propia en cada uno de los sexos, fue el de 26 a 40 años. Considerando las 22 áreas geográficas, en los varones esto no se cumplió en 8 áreas -en la metrópoli de la región Metropolitana; en las ATIs grandes, medias y pequeñas de la región Patagonia; en las ATIs medias y pequeñas, y pueblos grandes de la región Pampeana; y en las ATIs medias de Cuyo-, y en las mujeres sólo no se cumplió en la metrópoli de la región Metropolitana.

También a nivel total país, vemos que a medida que nos desplazamos a grupos de edades mayores, el porcentaje de asalariados privados en relación al total de ocupados, descendió; esta relación se produjo en ambos sexos, en los años 2001 y 2010.

Tal como puede observarse en los Cuadros 1 y 2, en los varones se produjo un descenso en las 22 áreas geográficas -con excepción de los pueblos grandes de Cuyo en el año 2010, entre los dos grupos de edades superiores-, en las mujeres sólo ocurrió en ocho áreas geográficas en 2001 -en las 14 restantes se produjo un leve incremento entre los grupos de mayor edad de 41 a 55 años y 56 a 65 años-, y en 15 
áreas urbanas en 2010 -en las restantes seis se produjo un aumento en los grupos de mayor edad-.

También a nivel total país, vemos que a medida que nos hemos desplazado a grupos de edades mayores, el porcentaje de cuenta propia y jefes en relación al total de ocupados se ha ido incrementando, esto ocurrió para ambos sexos, en ambos años censales bajo estudio. Lanzillota (2009) analizando la situación de Uruguay, afirma que las actividades por cuenta propia, se concentran mayoritariamente en los tramos etarios que van de los 30 a los 64 años.

Tantos en los varones como en las mujeres se produjo un incremento relativo de ambas categorías ocupacionales en las 22 áreas geográficas en 2001 y 2010.

Los descensos más importantes a nivel total país en el porcentaje de asalariados sobre los distintos grupos de edad se produjeron entre los grupos de 26 a 40 años y 41 a 55 años en los dos últimos años censales. Entre las 22 áreas geográficas generadas, esto se verificó en 11 en el año 2001, y en todas las áreas geográficas en el año 2010. En el caso de las mujeres, la mayor disminución del porcentaje de asalariadas se presentó entre los grupos de 14 a 25 años y 26 a 40 años en los años 2001 y 2010. Considerando la división del espacio urbano en 22 áreas, en el año 2001 se cumplió en todas las áreas, y en el año 2010 en 15 áreas geográficas.

Los aumentos más importantes a nivel total país en los porcentajes de cuenta propia $^{11}$ sobre los distintos grupos de edad se produjeron entre los grupos de 56 a 65 años y más de 65 años en los varones y en las mujeres, en los dos años censales bajo análisis.

En los varones esto se cumplió en el año 2001 en 20 áreas geográficas (las excepciones son las ATIs grandes de la Patagonia con una reducción entre los grupos de 26 a 40 años y 41 a 55 años, y los pueblos grandes de la región Pampeana con un descenso entre los dos grupos de menor edad), en el año 2010 se verificó en 19 áreas geográficas (con la excepción de las metrópolis, las ATIs pequeñas y los pueblos grandes de la región Pampeana, entre los grupos de 26 a 40 años y 41 a 55 años). En las mujeres en el año 2001 se produjo en 19 áreas geográficas (las excepciones son la metrópolis de la región Metropolitana en la cual se verificó entre los grupos de 26 a 40 años y 41 a 55 años; y las áreas de las metrópolis y ATIs medias de la región Pampeana en los grupos de 14 a 25 años y 26 a 40 años); y en el año 2010 se cumplió en 17 de las 22 áreas urbanas definidas (las excepciones son las metrópolis y ATIs grandes de la región Pampeana; las ATIs pequeñas y pueblos grandes de Cuyo; las ATIs pequeñas del Noroeste, en todas estas áreas el aumento relativo más elevado se produjo entre los grupos de 41 a 55 años y 56 a 65 años )

11 Rissman (2003) distingue principalmente dos tipos de trabajadores a cuenta propia: Trabajadores independientes que deciden empezar sus propios negocios, tomando altos riesgos, para obtener grandes ganancias, y trabajadores que deciden empezar un negocio debido a que su actual trabajo no les satisface o simplemente porque se encuentran desempleados. 
Cuadro 1. Participaciones relativas de los ocupados y ocupadas en las categorías ocupacionales seleccionadas (como \% del total), según grupos de edad y sexo, por área geográfica definida. Argentina. Años 2001.

\begin{tabular}{|c|c|c|c|c|c|c|c|c|c|c|c|c|}
\hline \multirow{3}{*}{$\begin{array}{l}\text { Categoría } \\
\text { Urbana }\end{array}$} & \multirow{3}{*}{ Región } & \multirow{3}{*}{$\begin{array}{c}\text { Categorías } \\
\text { Ocupacionales }\end{array}$} & & orcentaje & del total & de Ocupa & ados & & orcentaje & del total & de Ocup & adas \\
\hline & & & & Grupo & $s$ de edad & (en años) & & & Grupos & $s$ de edad ( & (en años) & \\
\hline & & & 14 a 25 & 26 a 40 & 41 a 55 & 56 a 65 & más de 65 & 14 a 25 & 26 a 40 & 41 a 55 & 56 a 65 & más de 65 \\
\hline & & \begin{tabular}{|l|} 
Asalariados(as) privado \\
\end{tabular} & 63,9 & 53,2 & 39,8 & 34,9 & 23,4 & 71,9 & 51,0 & 40,9 & 40,7 & 37,2 \\
\hline Total & & \begin{tabular}{|l|l}
$\operatorname{Jefes}($ as $)$ \\
\end{tabular} & 1,8 & 5,5 & 9,7 & 13,5 & 19,9 & 1,4 & 3,4 & 5,5 & 7,4 & 10,3 \\
\hline & & Cuenta propia & 15,7 & 20,9 & 27,9 & 31,9 & 41,3 & 8,7 & 12,5 & 16,0 & 20,7 & 31,8 \\
\hline & & \begin{tabular}{|l|} 
Asalariados(as) privado \\
\end{tabular} & 71,7 & 61,7 & 47,4 & 41,5 & 28,5 & 77,4 & 61,3 & 49,0 & 45,7 & 42,5 \\
\hline & Metropolitana & \begin{tabular}{|l|l} 
Jefes(as) \\
\end{tabular} & 1,8 & 5,5 & 10,1 & 13,3 & 19,1 & 1,2 & 3,1 & 5,8 & 7,2 & 9,3 \\
\hline & & Cuenta propia & 12,1 & 18,2 & 26,5 & 29,5 & 38,2 & 6,9 & 11,8 & 17,4 & 19,9 & 29,3 \\
\hline Metropolis & & \begin{tabular}{|l|} 
Asalariados(as) privado \\
\end{tabular} & 65,9 & 54,9 & 39,3 & 34,0 & 21,2 & 73,5 & 53,9 & 41,7 & 40,8 & 36,3 \\
\hline & Pampeana & Jefes(as) & 2,1 & 5,7 & 9,4 & 12,5 & 17,6 & 1,6 & 4,0 & 5,8 & 7,0 & 9,1 \\
\hline & & Cuenta propia & 17,3 & 23,4 & 32,0 & 36,1 & 46,5 & 10,5 & 16,8 & 19,9 & 24,7 & 36,9 \\
\hline & & \begin{tabular}{|l|} 
Asalariados(as) privado \\
\end{tabular} & 50,5 & 39,0 & 25,3 & 20,8 & 16,4 & 67,4 & 41,3 & 29,7 & 29,8 & 27,8 \\
\hline & Noreste & \begin{tabular}{|l|l} 
Jefes(as) \\
\end{tabular} & 2,1 & 4,3 & 6,4 & 8,8 & 15,1 & 1,7 & 3,0 & 3,9 & 5,1 & 9,8 \\
\hline & & Cuenta propia & 27,1 & 26,4 & 29,7 & 32,8 & 38,9 & 12,0 & 13,9 & 14,2 & 17,7 & 32,4 \\
\hline & & Asalariados(as) privado & 56,4 & 47,5 & 32,9 & 28,2 & 17,2 & 73,4 & 51,1 & 37,9 & 37,0 & 33,5 \\
\hline & Noroeste & \begin{tabular}{|l|l}
$\operatorname{Jefes}(\mathrm{as})$ \\
\end{tabular} & 1,7 & 3,9 & 6,1 & 8,2 & 14,5 & 1,3 & 3,0 & 3,8 & 5,6 & 8,1 \\
\hline & & Cuenta propia & 27,2 & 28,3 & 33,1 & 37,6 & 49,8 & 12,5 & 16,2 & 16,9 & 22,7 & 37,3 \\
\hline & & Asalariados(as) privado & 62,4 & 50,6 & 35,5 & 28,7 & 19,2 & 71,7 & 48,8 & 37,7 & 37,6 & 36,6 \\
\hline Alis & Cuyo & Jefes(as) & 1,6 & 4,6 & 7,8 & 9,6 & 16,5 & 1,4 & 2,7 & 4,2 & 5,5 & 9,4 \\
\hline & & Cuenta propia & 20,3 & 24,1 & 30,3 & 32,9 & 47,3 & 10,5 & 12,8 & 15,6 & 21,9 & 33,1 \\
\hline & & Asalariados(as) privado & 60,1 & 47,0 & 33,6 & 29,5 & 23,0 & 67,0 & 46,4 & 36,1 & 37,2 & 39,2 \\
\hline & Pampeana & \begin{tabular}{|l|} 
Jefes(as) \\
\end{tabular} & 2,3 & 6,3 & 10,0 & 13,8 & 19,2 & 1,9 & 3,8 & 5,9 & 7,3 & 9,8 \\
\hline & & Cuenta propia & 16,7 & 20,7 & 25,9 & 30,5 & 40,3 & 9,2 & 11,5 & 14,1 & 17,6 & 28,7 \\
\hline & & \begin{tabular}{|l|} 
Asalariados(as) privado \\
\end{tabular} & 62,7 & 50,4 & 36,8 & 31,4 & 21,3 & 67,4 & 44,7 & 36,0 & 41,0 & 36,9 \\
\hline & Patagonia & Jefes(as) & 1,5 & 4,4 & 8,4 & 12,6 & 22,0 & 1,3 & 3,0 & 5,1 & 8,2 & 11,7 \\
\hline & & Cuenta propia & 14,6 & 18,1 & 26,2 & 30,2 & 37,7 & 7,8 & 9.2 & 13,1 & 17,4 & 32,1 \\
\hline & & Asalariados(as) privado & 53,2 & 40,2 & 27,2 & 23,2 & 16,7 & 73,8 & 41,9 & 31,5 & 29,7 & 22,5 \\
\hline & Noreste & Jefes(as) & 1,9 & 4,5 & 7,1 & 10,2 & 16,1 & 1,5 & 3,1 & 4,4 & 6,5 & 12,0 \\
\hline & & Cuenta propia & 25,3 & 24,6 & 27,5 & 32,7 & 42,4 & 10,2 & 13,0 & 14,1 & 21,9 & 35,4 \\
\hline & & \begin{tabular}{|l|} 
Asalariados(as) privado \\
\end{tabular} & 52,5 & 40,7 & 27,8 & 24,7 & 16,0 & 67,6 & 41,8 & 29,1 & 30,0 & 29,0 \\
\hline & Noroeste & \begin{tabular}{|l|l}
$\operatorname{Jefes}(\mathrm{as})$ \\
\end{tabular} & 1,5 & 3,5 & 5,4 & 8,3 & 13,0 & 1,2 & 2,4 & 3,2 & 4,9 & 8,2 \\
\hline & & Cuenta propia & 24,9 & 24,9 & 28,5 & 36,2 & 49,8 & 11,0 & 12,5 & 14,5 & 25,1 & 38,0 \\
\hline & & Asalariados(as) privado & 64,3 & 55,1 & 37,3 & 29,5 & 19,7 & 66,1 & 44,7 & 36,2 & 36,8 & 32,1 \\
\hline Ans & Cuyo & Jefes(as) & 1,5 & 4,3 & 7,6 & 10,2 & 17,6 & 1,2 & 3,3 & 4,5 & 6,0 & 9,4 \\
\hline & & Cuenta propia & 15,9 & 21,0 & 29,6 & 32,0 & 47,4 & 9,1 & 11,3 & 12,5 & 16,4 & 34,6 \\
\hline & & Asalariados(as) privado & 61,9 & 50,2 & 36,6 & 31,0 & 19,5 & 70,1 & 48,1 & 39,2 & 40,0 & 38,5 \\
\hline & Pampeana & Jefes(as) & 2,2 & 6,9 & 11,7 & 16,3 & 24,0 & 1,7 & 4,4 & 6,7 & 8,7 & 11,2 \\
\hline & & Cuenta propia & 15,4 & 20,9 & 27,6 & 32,6 & 42,3 & 9,7 & 12,8 & 14,7 & 19,6 & 31,7 \\
\hline & & \begin{tabular}{|l|} 
Asalariados(as) privado \\
\end{tabular} & 60,3 & 50,3 & 38,1 & 32,8 & 22,1 & 65,7 & 44,9 & 37,3 & 42,6 & 38,0 \\
\hline & Patagonia & Jefes(as) & 1,3 & 4,1 & 7,7 & 11,9 & 19,1 & 1,2 & 2,9 & 4,8 & 7,3 & 10,9 \\
\hline & & Cuenta propia & 13,8 & 15,7 & 23,3 & 30,1 & 40,2 & 7,9 & 9,2 & 12,1 & 18,4 & 28,7 \\
\hline & & \begin{tabular}{|l|} 
Asalariados(as) privado \\
\end{tabular} & 58,7 & 43,0 & 31,0 & 25,8 & 19,0 & 74,9 & 43,5 & 36,6 & 35,7 & 32,4 \\
\hline & Noreste & Jefes(as) & 1,9 & 4,9 & 8,3 & 12,0 & 17,8 & 1,3 & 3,0 & 4,6 & 7,9 & 11,4 \\
\hline & & Cuenta propia & 21,6 & 26,1 & 32,0 & 36,8 & 44,7 & 9,7 & 13,0 & 14,5 & 21,6 & 32,4 \\
\hline & & \begin{tabular}{|l|} 
Asalariados(as) privado \\
\end{tabular} & 61,5 & 49,2 & 38,0 & 33,4 & 20,2 & 69,5 & 39,5 & 29,7 & 30,8 & 26,2 \\
\hline & Noroeste & Jefes(as) & 1,6 & 3,6 & 5,5 & 7,6 & 12,9 & 1,1 & 2,7 & 3,5 & 4,9 & 9,1 \\
\hline & & Cuenta propia & 19,0 & 21,6 & 25,6 & 30,0 & 44,5 & 10,6 & 11,6 & 14,2 & 22,0 & 36,8 \\
\hline & & Asalariados(as) privado & 68,0 & 49,5 & 36,0 & 30,5 & 20,0 & 70,1 & 38,9 & 34,7 & 39,7 & 32,6 \\
\hline $\begin{array}{c}\text { A11s } \\
\text { Pequeñas }\end{array}$ & Cuyo & Jefes(as) & 1,3 & 4,1 & 7,3 & 10,8 & 19,4 & 0,7 & 1,9 & 3,7 & 6,2 & 9,7 \\
\hline Pequeñas & & Cuenta propia & 14,3 & 20,0 & 27,9 & 29,7 & 46,8 & 7,6 & 8,5 & 12,7 & 22,3 & 36,8 \\
\hline & & Asalariados(as) privado & 66,1 & 50,6 & 35,5 & 29,9 & 19,0 & 73,4 & 48,4 & 39,6 & 41,5 & 39,7 \\
\hline & Pampeana & Jefes(as) & 2,5 & 8,2 & 13,9 & 18,7 & 26,2 & 2,1 & 5,0 & 7,2 & 9,0 & 12,3 \\
\hline & & Cuenta propia & 14,6 & 22,6 & 30,2 & 34,7 & 43,2 & 8,4 & 12,3 & 14,7 & 19,5 & 31,2 \\
\hline & & Asalariados(as) privado & 61,1 & 49,2 & 39,6 & 35,9 & 22,4 & 62,9 & 38,9 & 34,5 & 39,4 & 32,8 \\
\hline & Patagonia & Jefes(as) & 1,3 & 4,1 & 7,8 & 11,8 & 22,9 & 0,8 & 2,6 & 4,8 & 9,9 & 15,8 \\
\hline & & Cuenta propia & 11.8 & 15.8 & 21.9 & 24,6 & 35,5 & 7,3 & 8,3 & 11.4 & 17,9 & 28,5 \\
\hline & & \begin{tabular}{|l|} 
Asalariados(as) privado \\
\end{tabular} & 58,3 & 41,3 & 31,9 & 27,9 & 16,6 & 69,8 & 34,0 & 29,2 & 29,1 & 26,2 \\
\hline & Noreste & Jefes(as) & 1,5 & 4,0 & 6,7 & 9,9 & 15,1 & 1,3 & 2,5 & 3,9 & 7,1 & 10,4 \\
\hline & & Cuenta propia & 19,8 & 23,0 & 27,4 & 33,1 & 43,3 & 10,3 & 11,2 & 14,6 & 25,6 & 37,1 \\
\hline & & Asalariados(as) privado & 59,3 & 42,1 & 33,1 & 31,2 & 18,2 & 64,9 & 32,8 & 26,2 & 25,3 & 20,2 \\
\hline & Noroeste & Jefes(as) & 1,2 & 2,8 & 4,2 & 5,8 & 10,6 & 1,1 & 1,8 & 2,8 & 4,5 & 8,5 \\
\hline & & Cuenta propia & 19,4 & 21,1 & 24,6 & 31,2 & 45,1 & 10,8 & 11,7 & 14,9 & 27,2 & 42,4 \\
\hline & & Asalariados(as) privado & 67,9 & 51,8 & 38,2 & 35,1 & 26,7 & 69,0 & 41,9 & 37,3 & 40,2 & 33,0 \\
\hline Prebios & Cuyo & Jefes(as) & 1,4 & 3,7 & 6,9 & 8,6 & 16,5 & 1,3 & 2,6 & 4,9 & 6,1 & 11,5 \\
\hline & & Cuenta propia & 12,8 & 19,6 & 25,1 & 27,0 & 39,1 & 7,3 & 10,8 & 13,8 & 20,3 & 33,2 \\
\hline & & \begin{tabular}{|l|} 
Asalariados(as) privado \\
\end{tabular} & 65,9 & 49,5 & 34,7 & 28,4 & 16,9 & 71,1 & 44,4 & 39,6 & 41,7 & 38,0 \\
\hline & Pampeana & Jefes(as) & 2,5 & 8,9 & 14,9 & 20,2 & 29,2 & 1,9 & 5,0 & 7,0 & 10,0 & 13,4 \\
\hline & & Cuenta propia & 12,9 & 22,1 & 29,7 & 33,9 & 41,1 & 8,2 & 12,1 & 14,4 & 20,2 & 30,8 \\
\hline & & Asalariados(as) privado & 56,0 & 43,6 & 32,6 & 28,0 & 20,6 & 59,9 & 34,6 & 30,3 & 35,2 & 32,0 \\
\hline & Patagonia & Jefes(as) & 1,4 & 4,1 & 7,7 & 12,9 & 19,4 & 1,1 & 2,8 & 4,7 & 8,5 & 13,2 \\
\hline & & Cuenta propia & 12,5 & 15,8 & 23,3 & 30,0 & 38,0 & 7,9 & 8,6 & 11,8 & 18,2 & 31.2 \\
\hline & & & & & & & & & & & Regio & iones: \\
\hline & & & & & & & & & & & & Metropolitana \\
\hline & & & & & & & & & & & & Pampeana \\
\hline & & & & & & & & & & & & Noroeste \\
\hline & & & & & & & & & & & & Nordeste \\
\hline & & & & & & & & & & & & Cuyo \\
\hline & & & & & & & & & & & & Patagonia \\
\hline
\end{tabular}

Fuente: Elaboración personal en base a datos del Censo Nacional de Población de 2001, procesado con Redatam+Sp. 
Cuadro 2. Participaciones relativas de los ocupados y ocupadas en las categorías ocupacionales seleccionadas (como \% del total), según grupos de edad y sexo, por área geográfica definida. Argentina. Años 2010.

\begin{tabular}{|c|c|c|c|c|c|c|c|c|c|c|c|c|}
\hline \multirow{3}{*}{$\begin{array}{c}\text { Categoría } \\
\text { Urbana }\end{array}$} & \multirow{3}{*}{ Región } & \multirow{3}{*}{$\begin{array}{c}\text { Categorías } \\
\text { Ocupacionales }\end{array}$} & & orcentaje & del total & de Ocupa & ados & & orcentaje & del total c & de Ocupa & adas \\
\hline & & & & Grupo & de edad & en años) & & & Grupo & $s$ de edad (e & en años) & \\
\hline & & & 14 a 25 & 26 a 40 & 41 a 55 & 56 a 65 & más de 65 & 14 a 25 & 26 a 40 & \begin{tabular}{|l|l|}
41 a 55 \\
\end{tabular} & 56 a 65 & más de 65 \\
\hline & & Asalariados(as) privado & 66,2 & 58,8 & 45,1 & 38,3 & 27,8 & 64,2 & 52,1 & 40,4 & 35,7 & 29,1 \\
\hline Total & & Jefes(as) & 2,5 & 5,9 & 10,0 & 12,8 & 18,0 & 2,6 & 4,7 & 6,5 & 8,8 & 13,2 \\
\hline & & Cuenta propia & 14,8 & 16,1 & 22,1 & 27,4 & 36,2 & 15,5 & 15,3 & 18,4 & 24,8 & 36,0 \\
\hline & & Asalariados(as) privado & 70,5 & 65,0 & 52,2 & 44,0 & 31,6 & 69,8 & 60,7 & 48,9 & 41,9 & 33,3 \\
\hline & Metropolitana & Jefes(as) & 2,3 & 5,4 & 9,3 & 12,2 & 16,3 & 2,2 & 4,1 & 6,1 & 7,6 & 11,2 \\
\hline Metróngli & & Cuenta propia & 11,5 & 13,3 & 20,0 & 26,1 & 35,9 & 12,0 & 13,2 & 18,7 & 24.9 & 35,4 \\
\hline Metrópolis & & Asalariados(as) privado & 67,7 & 60,1 & 44,4 & 36,2 & 24,5 & 65,6 & 54,9 & 39,8 & 33,0 & 27,7 \\
\hline & Pampeana & Jefes(as) & 2,7 & 6,8 & 10,9 & 13,0 & 17,6 & 3,1 & 5,7 & 7,8 & 10,8 & 13,1 \\
\hline & & Cuenta propia & 16.5 & 18,2 & 26,3 & 33,4 & 41,3 & 18,3 & 19.4 & 24,3 & 30,3 & 39,1 \\
\hline & & Asalariados(as) privado & 53,4 & 48,7 & 31,9 & 26,5 & 17,0 & 56,1 & 41,6 & 28,4 & 23,9 & 17,2 \\
\hline & Noreste & Jefes(as) & 2,8 & 5,9 & 8.9 & 10,6 & 16,5 & 4,0 & 5,4 & 6,6 & 8.4 & 15,5 \\
\hline & & \begin{tabular}{|l|} 
Cuenta propia \\
\end{tabular} & 23,6 & 21,2 & 25,8 & 30,6 & 42,9 & 20,3 & 20,8 & 20,2 & 27,3 & 38,8 \\
\hline & & Asalariados(as) privado & 56,8 & 52,5 & 37,7 & 29,5 & 19,0 & 55,7 & 47,0 & 33,2 & 28,4 & 22,6 \\
\hline & Noroeste & Jefes(as) & 1,8 & 4,5 & 7,4 & 10,5 & 16,4 & 2,1 & 4,2 & 5,1 & 7,5 & 14,6 \\
\hline & & Cuenta propia & 22,4 & 21,0 & 28,2 & 32,5 & 45,8 & 22,5 & 20,3 & 22,4 & 26,5 & 43,5 \\
\hline & & Asalariados(as) privado & 64,6 & 57,2 & 41,3 & 32,2 & 22,6 & 61,7 & 49,8 & 36,0 & 29,2 & 26,7 \\
\hline ATIs & Cuyo & Jefes(as) & 2,4 & 6,1 & 10,0 & 12,3 & 18,0 & 2,7 & 5,0 & 5,6 & 8,8 & 15,1 \\
\hline & & Cuenta propia & 18,0 & 19,2 & 25,8 & 30,4 & 39,3 & 20,0 & 18,8 & 21,5 & 28,3 & 38,3 \\
\hline & & Asalariados(as) privado & 60,2 & 51,0 & 37,2 & 31,2 & 21,2 & 58,6 & 46,4 & 35,6 & 29,4 & 22,2 \\
\hline & Pampeana & Jefes(as) & $\frac{2,7}{2,7}$ & 7,1 & 12,4 & 14,2 & 17,1 & 2,6 & 5,5 & 7,4 & 10,3 & 11,6 \\
\hline & & Cuenta propia & 19,5 & 18,5 & 23,4 & 29,4 & 43,7 & 21,2 & 17,7 & 19,3 & 24,9 & 45,2 \\
\hline & & Asalariados(as) privado & 64,3 & 59,1 & 42,3 & 38,1 & 27,9 & 63,9 & 48,5 & 39,8 & 36,6 & 26,7 \\
\hline & Patagonia & \begin{tabular}{|l|l} 
Jefes (as) \\
\end{tabular} & 3,2 & $\frac{3,7}{4,7}$ & 9,4 & 12,4 & 18,5 & 3,3 & $\frac{3,7}{3,7}$ & 5,2 & 10,7 & 18,6 \\
\hline & & Cuenta propia & 13,6 & 13,9 & 20,9 & 27,7 & 37,6 & 14,4 & 13,4 & 14,2 & 24,9 & 37,4 \\
\hline & & Asalariados(as) privado & 53,7 & 48,3 & 32,4 & 27,2 & 16,2 & 52,7 & 41,9 & 28,2 & 21,8 & 13,9 \\
\hline & Noreste & \begin{tabular}{|l|l} 
Jefes(as) \\
\end{tabular} & 2,1 & $\frac{40,3}{5.4}$ & $\frac{5,7}{8,7}$ & 11,4 & 17,2 & $\frac{2,3}{2,5}$ & $\frac{1,7}{5,2}$ & $\frac{20,2}{6,7}$ & 9,8 & 14,3 \\
\hline & & Cuenta propia & 23,2 & 21,4 & 26,3 & 29.6 & 34,7 & 23,0 & 20,3 & 20,5 & 24.8 & 34,3 \\
\hline & & Asalariados(as) privado & 55,2 & 48,0 & 33,1 & 25,6 & 18,0 & 52,7 & 41,1 & 26,5 & 20,3 & 17,9 \\
\hline & Noroeste & Jefes(as) & 2,7 & 5,4 & 8,3 & 9,0 & 13,9 & 3,1 & 4,5 & 5,1 & 7,5 & 9,9 \\
\hline & & Cuenta propia & 21,0 & 19.4 & 23,0 & 29,1 & 41,9 & 21,7 & 17,8 & 17,7 & 24,4 & 43,1 \\
\hline & & Asalariados(as) privado & $\frac{4,7}{64,7}$ & 55,6 & 41,9 & 29,1 & 21,3 & 57,6 & 41,7 & 32,2 & 29,7 & $\frac{7,1}{27,4}$ \\
\hline ATIs & Cuyo & \begin{tabular}{|l|} 
Jefes(as) \\
\end{tabular} & 3,0 & 6,6 & 11,1 & 14,1 & 25,2 & 3,0 & 5,6 & 6,2 & 9,2 & 24,7 \\
\hline & & Cuenta propia & 16,7 & 16.8 & 24,3 & 27,1 & 38.0 & 21,4 & 16,2 & 17,1 & 19,3 & 28,5 \\
\hline & & Asalariados(as) privado & 66,6 & 56,0 & 41,0 & 33,4 & 20,8 & 64,6 & 50,3 & 39,4 & 33,4 & 25,6 \\
\hline & Pampeana & Jefes(as) & 2,8 & 8,0 & 13,7 & 17,3 & 24,6 & 2,9 & 6,4 & 8,3 & 11,3 & 16,3 \\
\hline & & \begin{tabular}{|l|} 
Cuenta propia \\
\end{tabular} & 14,8 & 17,0 & 23,4 & 30,4 & 39,6 & 16,6 & 15,8 & 17,8 & 26,0 & 37,8 \\
\hline & & Asalariados(as) privado & 62,7 & 58,5 & 42,0 & 36,8 & 22,7 & 58,7 & 47,6 & 35,7 & 34,7 & 27,4 \\
\hline & Patagonia & Jefes(as) & 2,6 & 5,0 & 9,7 & 13,6 & 20,4 & 2,8 & 3,7 & 6,9 & 8.9 & 19,5 \\
\hline & & Cuenta propia & 14,5 & 13,5 & 19,9 & 26,1 & 36,8 & 15,1 & 12,4 & 15,6 & 23,6 & 32,7 \\
\hline & & Asalariados(as) privado & 63,1 & 51,6 & 36,6 & 32,9 & 22,5 & 61,5 & 43,8 & 31,5 & 28,9 & 24,2 \\
\hline & Noreste & Jefes(as) & $\frac{2,3}{2,9}$ & 6,1 & 8,7 & 10,5 & 15,0 & 3,5 & 5,2 & 6.2 & 8.8 & 13,0 \\
\hline & & Cuenta propia & 16,1 & 20,1 & 27,0 & 31,3 & 39,1 & 16,1 & 16,3 & 18,9 & 24,8 & 35,5 \\
\hline & & Asalariados(as) privado & 67,8 & 59,4 & 46,7 & 40,7 & 31,0 & 62,9 & 44,5 & 30,2 & 27,5 & 28,4 \\
\hline & Noroeste & Jefes(as) & 1,3 & 2,9 & 4,7 & 5,5 & 7,3 & 1,8 & 2,5 & 3,7 & 5,2 & 6,0 \\
\hline & & Cuenta propia & 15,2 & 16,7 & 20,2 & 24.5 & 39.4 & 17,7 & 16,4 & 15,2 & 24.8 & 40,1 \\
\hline & & Asalariados(as) privado & 71,1 & 60,2 & 46,7 & 42,0 & 40,8 & 67,7 & 45,2 & 38,1 & 40,4 & 41,5 \\
\hline ATIs & Cuyo & Jefes(as) & 1,3 & 2,0 & 2,4 & 3,0 & 3,7 & 1,2 & 1,3 & 1,6 & 2,4 & 3,1 \\
\hline & & Cuenta propia & 12,2 & 13,8 & 17,5 & 22,3 & 30,6 & 12,3 & 10,5 & 12,0 & 17,7 & 29,1 \\
\hline & & Asalariados(as) privado & 68,6 & 56,3 & 42,6 & 36,9 & 29,0 & 67,0 & 50,7 & 40,4 & 38,6 & 32,9 \\
\hline & Pampeana & Jefes(as) & 2,7 & 8,4 & 13,6 & 17,2 & 24,3 & 2,8 & 5,9 & 8,1 & 10,9 & 17,0 \\
\hline & & \begin{tabular}{|l} 
Cuenta propia \\
\end{tabular} & 13,7 & 16,7 & 22,0 & 25,8 & 30,3 & 14,0 & 14,2 & 0,1 & 20,8 & 29,9 \\
\hline & & Asalariados(as) privado & 67,6 & 62,0 & 49,6 & 46,8 & 35,8 & 63,6 & $\frac{4,2}{46,9}$ & 38,5 & 42,5 & 36,2 \\
\hline & Patagonia & Jefes(as) & 1,6 & 4,3 & 7,8 & 10,1 & 16,7 & 1,6 & 3,4 & 5,3 & 7,9 & 12,2 \\
\hline & & \begin{tabular}{|l} 
Cuenta propia \\
\end{tabular} & 12,3 & 10,5 & 15,6 & 20,8 & 26,5 & 14,0 & 9,1 & 11,3 & 16,7 & 26,5 \\
\hline & & Asalariados(as) privado & 58,0 & 48,7 & 35,4 & 32,3 & 22,3 & 54,2 & 35,3 & 24,8 & 23,5 & 19,6 \\
\hline & Noreste & Jefes(as) & 2,3 & 3,7 & 5,1 & 6,3 & 9,6 & 2,6 & 3,1 & 3,7 & 5,5 & 8,8 \\
\hline & & Cuenta propia & 19,0 & 20,9 & 25,4 & 30,6 & 39,1 & 18,7 & 18,1 & 18,7 & 26,8 & 38,4 \\
\hline & & Asalariados(as) privado & 63,3 & 53,9 & 39,0 & 35,8 & 26,9 & 57,5 & 38,3 & 25,1 & 24,2 & 26,4 \\
\hline & Noroeste & Jefes(as) & 1,2 & 1,8 & 2,2 & 3,0 & 4,4 & 1,6 & 1,8 & 1,8 & 2,7 & 3,9 \\
\hline & & Cuenta propia & 16,5 & 16,6 & 19,6 & 23,9 & 37,5 & 18,0 & 15,7 & 16,6 & 24,8 & 37,7 \\
\hline & & Asalariados(as) privado & 72,1 & 61,7 & 48,9 & 44,4 & 44,8 & 66,7 & 46,2 & 38,5 & 38,2 & 43,2 \\
\hline Pueblos & Cuyo & Jefes(as) & 0,9 & $\frac{1,7}{1,7}$ & $\frac{23}{23}$ & 28 & 4,5 & 1,3 & $\frac{10,2}{1.5}$ & 2,0 & $\frac{2.2}{2.9}$ & 3,7 \\
\hline & & Cuenta propia & 12,7 & 14.4 & 19.9 & 22,0 & 29,4 & 14,8 & 13,2 & 15,5 & 21,4 & 30,2 \\
\hline & & Asalariados(as) privado & 69,3 & 55,2 & 41,1 & 34,4 & 25,6 & 65,5 & 46,4 & 38.5 & 37,2 & 29.5 \\
\hline & Pampeana & Jefes(as) & 3,7 & 9,6 & 15,4 & 19,1 & 26,8 & 4,2 & 7,1 & 9,0 & 12,8 & 20,7 \\
\hline & & Cuenta propia & 12,4 & 16,5 & 22,0 & 25,8 & 31,1 & 13,2 & 13,6 & 14.8 & 20,5 & 29.3 \\
\hline & & Asalariados(as) privado & 61,8 & 53,4 & 41,4 & 38,8 & 33,7 & 58,3 & 40,5 & 31,7 & 33,8 & 34,1 \\
\hline & Patagonia & Jefes(as) & 1,9 & 3,7 & 6,3 & 9,3 & 15,0 & 2,5 & 3,3 & 4,4 & 7,1 & 12,7 \\
\hline & & Cuenta propia & 10.8 & 10.2 & 13.5 & 18.3 & 23,5 & 10,8 & 8.8 & 9.6 & 14.9 & 24,0 \\
\hline & & & & & & & & & & & Regio & iones: \\
\hline & & & & & & & & & & & & Metropolitana \\
\hline & & & & & & & & & & & & Pampeana \\
\hline & & & & & & & & & & & & Noroeste \\
\hline & & & & & & & & & & & & Nordeste \\
\hline & & & & & & & & & & & & Cuyo \\
\hline & & & & & & & & & & & & Patagonia \\
\hline
\end{tabular}

Fuente: Elaboración personal en base a datos del Censo Nacional de Población de 2010, procesado con Redatam + Sp. 
En las 22 áreas geográficas la mayor cantidad de ocupados independientes en relación al total en ambos sexos, en los años 2001 y 2010, se produjo en el grupo de más de 65 años, siendo superior esta proporción en los varones respecto a las mujeres, con una sola excepción en las ATIs grandes de la Patagonia.

Bertranou (2001), afirma que cada generación tiene una situación más desventajosa que la anterior. Suponiendo que la situación de los trabajadores independientes es inferior a la de los dependientes. Sin embargo hemos verificado que entre los años 2001 y 2010, en los varones el porcentaje de dependientes en relación al total de ocupados, disminuyó en los varones a nivel total país y en todas las áreas geográficas -con una sola excepción, las ATIs grandes Pampeanas-, mientras que en las mujeres ocurrió lo contrario, se produjo un aumentó a nivel total país y en las 22 áreas geográficas. Considerando los grupos de edad, en los varones se produjo un incremento del porcentaje de los trabajadores independientes en el grupo de 14 a 25 años en 5 áreas geográficas, en el grupo de 41 a 55 años en 2 áreas geográficas, en el de 56 a 65 años en una área geográfica, y en los mayores de 65 años en 2 áreas geográficas. En las mujeres se produjo un descenso en el grupo de 41 a 55 años en 3 áreas geográficas, en el grupo de 56 a 65 años en 6 áreas geográficas, y en los mayores de 65 años en 6 áreas geográficas.

\section{Conclusiones}

La relación entre el crecimiento económico y el comportamiento del mercado de trabajo no es para nada determinística en la Argentina, es necesario considerar este último en términos de un contexto más amplio, teniendo en cuenta el régimen económico dominante en cada periodo. Esto se refleja en la dinámica laboral del último periodo intercensal, en el que se destacó el marcado contraste en el nivel del desempleo, de alrededor de $22 \%$ en 2001 y $6 \%$ en el año 2010.

La PET tuvo un incremento de algo más del 13\% entre los años 2001 y 2010, no existiendo diferencias entre sexos. Considerando la división según grupos de edad de la PET, las variaciones demográficas (en la fecundidad, mortalidad y las migraciones), afectan de manera diferencial a los mismos. Resultando que el grupo de 14 a 25 años que era el más cuantioso en el año 2001, sea reemplazado por el de 26 a 40 años en el año 2010, en cada uno de los sexos, lo cual generó un incremento de la oferta de empleo, dado que la participación laboral de este grupo de edad fue superior. Además el aumento de la oferta de empleo fue marcadamente superior al crecimiento poblacional, en mayor medida en el caso de las mujeres. Esta mayor oferta de empleo en el último periodo intercensal se vinculó con una demanda de empleo aun muy superior -siendo más elevado en el caso de las trabajadoras-, lo que tuvo como resultado el marcado descenso del desempleo. Respecto a la problemática bajo estudio, que es el análisis de las distintas participaciones relativas de las categorías ocupacionales que toman los trabajadores y trabajadoras según la edad de los mismos. 
A pesar del crecimiento record del total de ocupados en el último periodo intercensal, que diferencia de manera notable el tamaño del mercado de trabajo del año 2001 y 2010 de Argentina, alrededor del 50\% del total de los ocupados y ocupadas, se insertaron como asalariados en el sector privado en ambos años. Las asalariadas en el sector público presentan un mayor peso relativo en el total de ocupadas que en los ocupados, manteniéndose estos porcentajes estables en ambos años censales.

En las categorías cuenta propia y jefes, entre el año 2001 y 2010 se presentó una disminución en la brecha de género. Mientras que la categoría de trabajadores familiares presentó un peso marginal y se mantuvo relativamente estable en ambos años censales.

En síntesis a nivel del total de los ocupados y ocupadas, las estructuras según categorías ocupacionales entre los años 2001 y 2010, presentaron marcada rigideces, y cierta tendencia a la convergencia entre sexos en las categorías ocupacionales correspondientes al empleo independiente, en el marco de un crecimiento de casi $70 \%$ de los puestos de trabajo.

A diferencia de la estructura según categoría ocupacional del total de ocupados, según grupos de edad las estructuras se modificaron marcadamente.

En el grupo de los jóvenes el porcentaje de los asalariados en el sector privado fue el más alto (en mayor medida en el caso de las mujeres), y los ocupaciones independientes (cuenta propia y jefe) presentaron una menor participación (siendo superior en los varones).

A medida que se incrementa la edad de los trabajadores de ambos sexos la inserción como cuenta propia o jefe crece en ambos años censales, es decir se incrementan las posibilidad de un trabajo independiente, alcanzándose el mayor porcentaje de trabajadores independientes en ambos sexos (siendo superior en los varones), en el grupo de 65 años y mas, en 2001 y 2010.

Considerando la división según las 22 áreas geográficas urbanas, se destacan determinadas heterogeneidades respecto a los patrones verificados a nivel total país, estas son:

-Se produjo un incremento del porcentaje de los trabajadores independientes en el grupo de 14 a 25 años en 5 áreas geográficas, en el grupo de 41 a 55 años en solo 2 áreas geográficas, en el de 56 a 65 años en un área geográfica, y en los mayores de 65 años en 2 áreas geográficas. En las mujeres se produjo un descenso en el grupo de 41 a 55 años en 3 áreas geográficas, en el grupo de 56 a 65 años en 6 áreas geográficas, y en los mayores de 65 años en 6 áreas geográficas.

-El grupo de edad con mayor cantidad de trabajadores cuenta propia difiere en 10 áreas geográficas en los varones y 14 en las mujeres en el año 2001 respecto al total país, en 8 áreas geográficas en los varones y en tan sólo una en las mujeres en el año 2010.

-El descenso en los trabajadores asalariados del sector privado según grupos 
de edad más elevado difiere del total país, en los varones en 11 áreas geográficas en el año 2001 y en las mujeres en 7 áreas geográficas en el año 2010.

\section{Referencias bibliográficas}

-ABELLAN, Antonio et. al. La población del mundo. Madrid: Editorial Síntesis, 1998.

-BERTRANOU, Fabio. Empleo, Retiro y Vulnerabilidad Socioeconómica de la Población Adulta Mayor en la Argentina. Serie fondo de investigaciones. Informes de la línea de investigaciones $\quad$ INDEC, 2001. Disponible $<$ http://www.indec.gov.ar/mecoviargentina/Bertranou.pdf $>$. Acceso 25 de diciembre de 2016.

-BERTRANOU, Fabio. Economía informal, trabajadores independientes y cobertura de la Seguridad Social en Argentina, Chile y Uruguay. Chile: OIT, 2007. Disponible en $<$ http://oit.org/wcmsp5/groups/public/---ed_emp/---

emp_policy/documents/meetingdocument/wcms_125982.pdf $>$. Acceso 12 de diciembre de 2016.

-BERTRANOU, Fabio y MAURIZIO, Roxana (Eds.) Trabajadores independientes, mercado laboral e informalidad en Argentina. Buenos Aires: OIT, 2011. Disponible en $<$ http://www.redetis.iipe.unesco.org/wp-content/uploads/2013/10/trab_indep_merc-Laborale-informalidad_OIT2011.pdf $>$. Acceso 15 de diciembre de 2016.

-BERTRANOU, Fabio y SARAVÍA, Leonor. Trabajadores independientes y la protección social en América Latina: desempeño laboral y cobertura de los programas de pensiones. En BERTRANOU, Fabio (Coord.), Trabajadores independientes y protección social en América Latina, OIT-BPS, 2009.

-PÉREZ, Pablo; DELEO, Camila y FERNÁNDEZ MASSI, Mariana. Desigualdades sociales en trayectorias laborales de jóvenes en la Argentina". Revista Latinoamericana de Población, v. 7, n. 13, p. 61-89, Julio-Diciembre, 2013.

-FERNÁNDEZ-HUERGA, Eduardo. La teoría de la segmentación del mercado de trabajo: enfoques, situación actual y perspectivas de futuro. Investigación Económica, v. 69, n. 273, p. 115-150, 2010. Disponible $<$ http://www.scielo.org.mx/scielo.php?script=sci_arttext\&pid=S0185$16672010000300004>$. Acceso 15 de diciembre de 2016.

-GHERARDI, Natalia y ZIBECCHI, Carla. El derecho al trabajo y la ocupación de las mujeres: una visión regional para América Latina. En DI PIETRO, Maria Paula (Comp.). Género y Empleo: iniciativas de la sociedad civil como modelos para la construcción de políticas públicas de empleo con mirada de género, 2010. Disponible en: $<$ http://www.ela.org.ar/a2/index.cfm?aplicacion=app187\&cnl=20\&opc=15>. Acceso $10 \mathrm{de}$ diciembre de 2016.

-GOYES, Oscar Hernán Muñoz. Factores determinantes de la participación laboral: aspectos conceptuales. Tendencias, v. 10, n 1, p. 87-116, 2009.

-JIMÉNEZ, Mónica. La economía informal y el mercado laboral en la Argentina: un análisis desde la perspectiva del Trabajo Decente. Tesis de maestría, Magister en Economía, Universidad Nacional de La Plata, 2011. Disponible en: 
$<$ http://sedici.unlp.edu.ar/handle/10915/3462>. Acceso 10 de diciembre de 2016.

-KERR, Clark. The Balkanization of labor markets. En BAKKE Wight et al. (eds), Labor Mobility and Economic Opportunity. Cambridge: Massachusetts, The MIT Press, 1954.

-KERR, Clark. The Neoclassical revisionists in labor economics (1940-1960) - R.I.P.". En KAUFMAN Bruce (ed.), How Labor Markets Work. Lexington, D.C: Heath and Co, 1988.

-LEPORE, Eduardo y SCHLESER, Diego. La heterogeneidad del cuentapropismo en la Argentina actual. Una propuesta de análisis y clasificación. Trabajo, ocupación y empleo, v. 4, p. 193-226, 2006.

-MANDELMAN, Federico y MONTES ROJAS, Gabriel. Microentrepreneurship and the Business Cycle: Is Self-Employment a Desired Outcome? Federal Reserve Bank of Atlanta, Working Paper 2007-15, 2007.

-MANZANO, Fernando y VELÁZQUEZ, Guillermo. Estructura ocupacional argentina. ¿Qué ocultan los promedios? Análisis según regiones y escala urbana. Año 2010. Papeles de geografía, n. 62, p. 9-20, 2016.

-MÁRQUEZ, Gustavo y MEZZERA, Jaime. A Model of Segmented Labor Markets. Discussion Paper Series, n. 79, 1988.

-NEFFA, Julio César. La teoría neoclásica ortodoxa sobre el funcionamiento del mercado de trabajo. El papel de los intermediarios. En V Congreso Nacional de Estudios del trabajo, 2001. Disponible en: <http://www.aset.org.ar/congresos/5/aset/pdf/neffa.pdf $>$. Acceso 10 de diciembre de 2016.

-NOVICK, Marta. ¿Emerge un nuevo modelo económico y social? El caso argentino 2003 2006. Revista Latinoamericana de Estudios del Trabajo (RELET), v. 11, n. 18, p. 53$78,2006$.

-OIT. Panorama Laboral 2006. Lima: OIT/ Oficina Regional para América Latina y el Caribe, 2006.

-PINTO, Aníbal. Naturaleza e implicaciones de la heterogeneidad estructural de la América Latina. Cincuenta años de pensamientos en la Cepal, Textos seleccionados, v. 2. Santiago de Chile: Comisión Económica para América Latina y el Caribe, 1998.

-PIORE, Michael y DOERINGER, Peter. Internal labor markets and manpower analysis. Lexington Mass: Heat, 1971.

-RAMOS, Joseph. El problema del empleo: Enfoques ortodoxos y estructurales. Cuadernos de economía, v. 30, n. 90,1993.

-RISSMAN, Ellen. Self-employment as an alternative to unemployment. Federal Reserve Bank of Chicago, Working Paper 2003-34, 2003.

-RISSMAN, Ellen. The Self-Employment Duration of Younger Men over the Business Cycle. Economic Perspectives, v. 30, n. 3, pp.14-27, 2006.

-ROJAS CHÁVEZ, 2005 ROJAS CHÁVEZ, Armando Mario. Algunos comentarios sobre aplicación del sistema de Seguridad Social Integral a los trabajadores independientes. 
Revista de Derecho, n. 23, p. 306-321, julio, 2005.

-SALA, Gabriela. Empleo y desempleo entre los adultos mayores argentinos. Documento

de trabajo n. 7, IELDE, Marzo, 2011. Disponible en: $<$ http://www.economicas.unsa.edu.ar/ielde/esp/documentos-de-trabajo.php>. Acceso 03 de diciembre de 2016.

-TORNAROLLI, Leopoldo y CONCONI, Adriana. Informalidad y movilidad laboral: un análisis empírico para Argentina. Documento de trabajo n. 59, CEDLAS, octubre, 2007.

-VAPNARSKY, César y GOROJOVSKY, Néstor. El crecimiento urbano en la Argentina. Buenos Aires: Grupo Editor Latinoamericano-IIED. 1990.

-VELÁZQUEZ, Guillermo. Geografía y Bienestar. Buenos Aires: Eudeba, 2008.

-WELLER, Jürgen. Los retos de la institucionalidad laboral en el marco de la transformación de la modalidad de desarrollo en América Latina. Serie Reformas Económicas, CEPAL, 1998.

-ZELLER, Norberto y RIVKIN, Ana. El empleo en la Administración Pública Nacional: estudio de la distribución de cargos y de las características de sus remuneraciones. INAP; Serie I, Desarrollo Institucional y Reforma del Estado, n. 69, 2003.

\footnotetext{
Fernando Ariel Manzano

Doctor en Demografía. Universidad Nacional de Córdoba. Licenciado en Economía. Universidad de Buenos Aires.

Licenciado en Sociología. Universidad de Buenos Aires.

Participó del equipo de Evaluación Demográfica del Censo Nacional de Población, Hogares y Viviendas 2010.

Ha sido evaluador de publicaciones, de programas/proyectos de investigación y desarrollo.

Investigador de la Universidad Nacional del Centro de la Provincia de Buenos Aires (UNCPBA). Tandil. Buenos Aires. Rep. Argentina.

Becario Postdoctoral del Centro Científico Tecnológico (CCT), Tandil. Rep.

Argentina.

Dr. Horacio Casco 4539 (1429) CABA. Rep. Argentina.

Email: fernando14979@hotmail.com
}

Recebido para publicação em outubro de 2016

Aprovado para publicação em janeiro de 2017 